Board and the Council needs to be faced during the coming year". And the House Commission on Information and Facilities, noting that there has been considerable confusion over the role of the council, suggests that "substantial revision of the Council's statu- tory function, or its abolition, be proposed on grounds that unless Council contributions are integrated more effectively in the policymaking process, its existence can only be a source of frustration and disharmony within the agency".
There is clearly going to be more debate before OTA is able to establish a comfortable role in which it acts as a long-term analyst and at the same time provides advice geared to Congress's short-term outlook.

\section{European science policy sought}

The European Commission recently unveiled proposals for a Community science policy. Progress towards the aim of a common approach, reports Chris Sherwell, may prove to be more pedestrian than the enthusiasts are prepared to admit.

If the expressions of satisfaction emanating from the vicinity of the Berlaymont Building in Brussels are anything to go by, Europe is now well on its way towards forging a science and technology policy for itself. The Commission of the EEC, which has its headquarters there, recently unveiled the results of a closed symposium which took place under its auspices in Milan towards the end of May.

The aim of the symposium was to gather suitable suggestions for guidelines regarding research and development which the Commission might present to the relevant Council of Ministers later this year. This it reckons to have achieved. Among the 100-odd participants were members of the European and the various national parliaments; members of the Commission and of the Economic and Social Committee (a consultative body serving the EEC and Euratom), and government officials; and the customary host of scientists, engineers, industrialists and trade unionists who help to make meetings like this more models of organisation than of representativeness.

The three-day symposium, at Milan's International Institute for Management of Technology, was organised by Directorate General XII (Research, Science and Education) of the Commission with the aid of CERD (the European Research and Development Committee), which is an independent 21-member body of scientists and engineers established by the Community in 1973 to advise the Commission on the formulation of a common science policy. It took place in the context of an effort finally launched two years ago to sow the first seeds of a revamped Community science and technology policy to replace the old sectoral approach of the previous sixteen years.

That effort in fact had its real beginnings many years ago, but it was only in January 1974 that the Council of Ministers found itself able to give expression to sentiments voiced at the Paris Heads of Government meeting in October 1972; the Council passed four resolutions which would provide a basis for a broad Community science and technology policy. The resolutions covered matters like coordination, participation in the European Science Foundation and programmes of action. The Commission was landed with the task of looking at the science policies of the nine member states with a view to producing Community-wide projects and a common approach externally.

The hope was that the terms of a full-blooded European science policy could be finalised by the end of 1976 . The Council, when it met again in June 1975, urged that discussions on the objectives of such a policy be held "without delay", and the Milan symposium, being the major part of those discussions, heralded the end of this first phase in the new Community approach. The next phase begins if and when the Council approves the recommendations of the symposium's five working parties, each of which aimed to tackle separate areas of interest.

\section{Recommendations}

The Commission document sumarising the working parties' recommendations, taken as a whole, does not make exciting reading, being littered throughout with empty phrases characteristic of all ostensibly agonising searches for lowest-common-denominator agreements. Hidden in the interstices of the Commission's denatured language, however, is some sort of basis for the optimism now being expressed so expansively by the Director General at DGXII, Herr Gunter Schuster. Here, in essence, is the gist of the recommendations.

Working Party I: Long term objectives and priorities. The group recommends that a suitable instrument "such as proposed in 'Europe +30 ', 'be established "at the earliest possible time", and that in the meantime a "small unit of specialists" be set up in or be linked to DGXII "without delay". Lord Kennet from Britain dissented on the latter point, arguing that such a staff should be actually in DGXII to avoid the danger of it becoming a substitute for Europe +30 .

Among the many areas of high priority for research in the long term, the working party includes Europe's ecological system, climatic changes, water management and food shortages.

Working Party II: Medium term objectives and priorities. The main theme informing this group's recommendations emphasises the need to do more to bring innovations to potential customers. The group wants to "make operational, within the Communities (the EEC, the European Coal and Steel Community and Euratom), structures for securing and examining research and development proposals coming from any public or private European organisation". It also wants "to relaunch the Community development contract procedure" reserved for European [group's italics] groups of enterprises and multinationals, and "to establish structures for conveying the Commission's intentions". A consultative comittee for industry is suggested.

More specifically, the group hopes that certain subjects now neglected or insufficiently developed will receive "special consideration"-among them, hydrographical problems arising out of the existence of multinational basins, European epidemiological research, recycling and reclamation, basic biological research, and ethical problems in genetic matters.

Interestingly, there is a frank acknowledgment of the constraints within which such a policy can work. The human and financial resources the EEC has at its disposal, the group says, "are not considerable", and are so concentrated as to prevent the needs of a real European policy being met over a wider field--and in certain fields, the group declares, the EEC could not be satisfied with the role of a mere catalyst. The scientific and technical activity of the EEC, it stresses, is "an essential part of a true European economic community", and it expresses its hope for a separate budget that would allow further progress.

Working Party III: Coordination of national policies. After recognising that a common policy can only be built up "slowly and step by step out of the coordination of national policies 
and common sections", this group deals with coordination in four fields.

In basic science, it says, "the selfcoordination of scientific groups, institutes, organisations and associations is the most important and useful instrument of coordination"-and here the group has in mind the cooperation already operating between Britain's SRC, France's CNRS, Germany's Max Planck Institutes, and so on. Where research is carried out almost totally by industry, coordination should be limited to the "harmonisation and coherent development of support activities in the member states".

Research and development for "public services and tasks", on the other hand, "is undoubtedly the central object for coordination in the Community", because in these spheres the national government have sufficient responsibilities. Finally, in the mixed sector ("the most difficult sector for coordination"), where it is noted that funds in all countries are heavily concentrated in a few areas (nuclear, space, electronics), the group states rather vacuously that projects performed by industry but financed by government "should not be excluded from coordination".

Working Party IV: Innovation policy. Industrial enterprise, says this group, is "the main actor in the innovation process", but it is governments which have to create a favourable climateand promotion of innovation at the Community level "is at present hampered by the lack of a common industrial policy", which it calls "a serious obstacle to the development of comprehensive industrial $\mathrm{R} \& \mathrm{D}$ programmes".

The Community, it says, can make "an important contribution" towards creating the right climate: among other things, it could support cooperation in long term industrial research and development (fusion, aerospace, solar energy), finance demonstration projects, make more

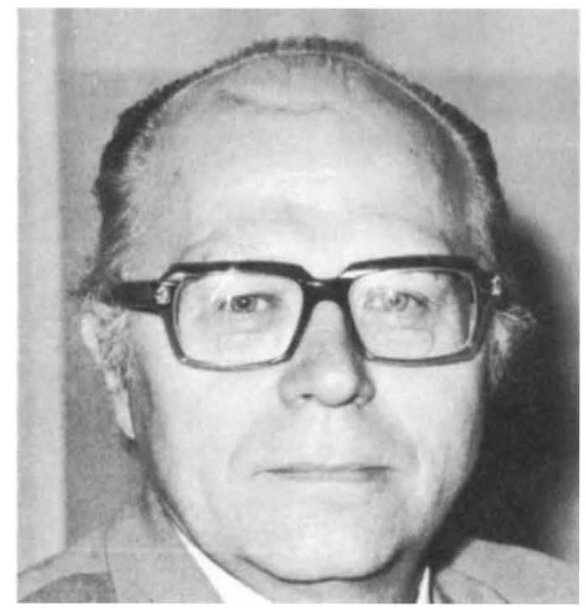

Herr Schuster, Director General at DGXII. accessible those public markets where state agencies are large buyers of technology, and improve access for small and medium sized industries to technological innovation. The group, like the second working party, recommends that the Commission set up an industry consultative committee to give industrial viewpoints on the Community's R\&D policy.

Far from judging the present economic plight of European countries a deterrent to innovation, the group rather believed this problem called for a special effort. Similarly, state participation in the field was less a constraint than a stimulus, although state encouragement of specific projectsnot so much in fields of obvious community interest (energy supply, public transport) as in fields like cybernetics -demanded fundamental discussion. The general feeling was that there was insufficient coincidence between the long term projects of member states and those of the Community-and that the liaison now lacking could, unsurprisingly, only be promoted through greater coordination. Plainly, though, the overlap with Europe's muchsought-after industrial policy is regarded as vital to the success of any research policy relating to industry.

Working Party V: Dissemination and exploitation of results. The group recommended that "a readily and selectively accessible dissemination system for information about R\&D" be set up within the Community, based on national information services and existing contacts between organisations. It further recommended that the Community's four-establishment Joint Research Centre (JRC) should have greater involvement in the exploitation of its own inventions, and that the Community should be able to provide companies with incentives where necessary (through exclusivity or lead times, for example). A small team of experts should also be available, with close links to scientists in the JRC and contractors, on the one hand, and to exploitation organisations in member states on the other.

\section{Long way to go}

All of which suggests that there is a long way to go before a real European policy is actually in operation. Although the recommendations reveal a rather limited number of specific institutional proposals, the general disposition in favour of a European approach, and one buttressed through additional budgetary support at that, shines through. The main emphasis, naturally enough, is on the key-word "coordination", perhaps the most crucial block in the fragile Community science edifice. But the question of how best this might be achieved, although begged throughout, does not receive a great deal in the way of answers.

Not that Europe's welter of institutions does not already include a goodly proportion of science-oriented bodies equipped to supply the answers. Apart from CERD, the most important is probably CREST, the Scientific and Technical Research Committee. It is the product of the January 1974 Council resolution on coordination, and is blessed with the task of "helping Community institutions to define objectives and securing the development of a common policy for science and technology." According to Working Party III, it is CREST which is to be regarded as the central committee where "coordination in all fields of R\&D is focused", and Community officials looking to CREST to translate proposals into reality do point to its achievements--in the implementation of Community projects on new energy sources and scientific information, for example, and in planning cooperation with non-Community countries, which it does within the context of COST, the Committee of Senior Officials in Scientific and Technical Research.

But there is little question about how much has really been achieved so far. No one at the Commission doubts that progress has been and will continue to be slow, or that CREST has yet to come into its own. There are pilot projects in hand, in the fields of energy, medical research and the determination of research and development indicators, and these represent practical attempts at coordination and alignment. For the moment, however, they merely supplement existing instruments of coordination, which also include the Advisory Committees on Programme Management (ACPMs).

The perspective being adopted in Europe is thus distinctly medium to long term-CERD itself has proposed that a European Science Year be organised in 1978 or 1979 , just before the United Nations World Science Year in 1980. In places the Commission's document makes a tilt towards the themes of humanising science and of Third World development, and there does seem to be an underlying view which argues that, if a European science policy is to have any chance of success at all, then somehow science itself will have to be brought closer to the proverbial man in the street, and be made to be seen as relevant to his needs. But if that laudable view is scuttled by the trials of actually identifying Europe's research requirements, and of formulating an acceptable policy (particularly regarding the distribution of its benefits and its burdens), there should be few surprised faces. 